\title{
Effect of Strategic Analysis and Strategy Implementation on Service Quality of a Popular Telecommunication Company in Nigeria
}

\author{
Aguoru, C.N., Umogbai, M.E. and Ozowa, V. \\ Department of Business Administration, University of Agriculture, Makurdi Nigeria \\ Corresponding author: Aguoru C.N (ndidiaguoru20@gmail.com)
}

\begin{abstract}
This study critically examined the effect of strategic planning and strategy implementation on the service quality of a popular telecommunication network provider in Nigeria. A survey research design was adopted through the use of structured questionnaires randomly administered to some MTN staff in the north central axis. Hypotheses were formulated followed by data validation, reliability and analysis using appropriate descriptive and inferential statistics. The Kaiser- Meyer- Olkin (KMO) test which measured the sample adequacy was 0.656 while the Bartlett's Test of Sphericity was significant $\left(X^{2}=84.362, p=\right.$ $0.000)$. The overall result was reliable with the Cronbach's Alpha values greater than 0.70 for each variable measured. Result showed that most of the workers (about 54\%) had 2-4years working experience with the organization while the longest length of service was approximately $12 \%$ in the work force. All the parameters measured were above the minimum agreeable benchmark of 3.5. The environment of the business affects its performance with a mean value of 4.12. There are enough resources to help the organization achieve its goal (4.3). The analysis of resources in the organization has helped improve the quality of services rendered (4.25). The adoption of strategic analysis by MTN helped in improving the service quality of company. Strategic analysis and strategy implementation each had significant relationship with service quality $\left(\mathrm{F}=25.48, \mathrm{p}=0.000, \mathrm{R}^{2}=53.5\right)$. All the seven indicators of service quality employed indicated high results. The organization is reliable with good assurance. Network quality recorded the highest mean (3.71). Other results such as competitive advantage and reliability (3.22) attested to the high service quality of the organization. With the average service quality of 3.09 , the corporate planning of MTN is oriented towards retaining customers through the provision of high quality of its service.
\end{abstract}

Key words: Service quality, Strategic analysis, Strategy implementation, Telecommunication

\section{Introduction}

A service is an activity or a series of activities of more or less intangible nature that normally, but not necessarily, takes place in interactions between the customer and service employees and/or systems of service providers, which are provided as solutions to customer problems (Akingbade, 2014). Service delivery can be taken to be an outcome of performance depending on the context in which it is used. According to Armstrong (1995), service can be expressed in terms of capacity to deliver desired services and from which customers get satisfaction. A service delivery gap is that gap between the established delivery standards and the actual service delivered. It is an inconsistency between service design / quality specifications and the actual service quality by the service delivery system. The American Society for Quality Control defines quality as: the totality of features and characteristics of a product or service that bear on its ability to satisfy stated or implied needs. Research on service quality has continued to grow for almost quarter a century now; satisfaction also depends on product and service quality (Armstrong, 1995). The seven dimensions of service quality according to Mohammed and John (2012) are: tangibility, reliability, responsiveness, assurance, empathy, network Quality and competitive advantage. 
As competition in the service industry grows, delivering high quality service to meet customers' needs is essential for success (Porter, 1985). Quality of service delivery has emerged as the most significant strategy in ensuring the survival of organizations and also a fundamental route to business excellence as well as extending market share of health care organizations (Imaga, 2000). This is because satisfaction has a positive relationship to patients' future decision to return to a facility to receive service. Service provision that is de-linked from citizen influence and democratic decision making is unlikely to deliver quality services for the poor. For meaningful contributions, the poor require the ability and capacity to ask questions and, sufficient information of their right and entitlements, service options, local and national budgets, and the systems to address when decisions are taken undemocratically or when services are of poor quality. Alaka et al. (2011) insisted that service delivery has to be communicated over and over again to everyone; the employees at all levels must be aligned with a single vision of what the organization is trying to accomplish. Thus, effective internal communications is the requisite for integration and harmony in the service organizations activities and quality. Richard (2002) also said that the goal of any social service organization is to improve the results of the target population in some way by providing the right type of services and by providing them in an appropriate and adequate way.

Strategic analysis is part of overall management process which is concerned with attempts to understand the strategic position of the organization, to consider goings-on in the environment and judge how the happenings can affect the organization. It also considers the organization's strengths and weaknesses with respects to the happenings and assesses the feelings of the stakeholders. Strategic analysis actually helps to form a picture of the factors that influence the organization so that it can be informed of the strategic choice element of the overall strategic management process (Griffins, 2006). Strategic analysis according to Garad et al. (2015) described the possible framework for such changes as PEST, political, economical, sociological and technical developments which help in improving on the quality of services offered. For an organization to sustain its business and remain competitive there must be constant, effective and environmental analyses to inform and allow the strategic decisions that keep the organization competitively healthy and quality of services increased (Hax and Majluf, 1996).

Strategy implementation involves the introduction and activation of the formulated strategy into an organization. Business managers take long period to develop and formulate strategies that are best suited for their organizations through the process of evaluating and selecting the best options available to them before arriving at the stage of implementing those strategies. Implementation of strategies takes a lot of will power from the management as there will always be resistance (Adeoye, 2015). Therefore, at this stage the management must be ready to confront, engage resistors and enforce the formulated strategies (Akingbade, 2014). However, caution must be taken to avoid undue confrontation between management and employees, so that it will not lead to overheating the system. Meanwhile, Ansoh et al. (2001) stated that some of the factors inducing the proper implementation of strategies include: lack of accountability, inadequate instructions to employees, culture, and power and influence. According to Alamutu et al. (2012) strategy implementation creates a link between strategy formulation and expected outcomes. It has been suggested that the successful execution of organizational strategies could boost organizational performance and reduce cost thereby improving the quality its services. They further explained that Nigerian Telecommunications have for the past years embarked on strategies that improve the quality of its services thereby remaining competitive in the market. Alaka et al. (2011) asserts that the failure to effectively implement strategies may lead to unanticipated loss in the organizations' performance in terms of service delivery and market share.

Even though the Nigerian Telecommunications sector has grown significantly in the past ten years, yet customers still complain of poor customer service, drop calls, high call rate, network blockage or congestion, and service quality problems. Piqued by this falling standard of quality of services, the Nigerian Telecommunications Commission had to slam a whopping sum of N1.17billion fine on all four (4) GSM operators. This problem of service quality may be due to poor corporate planning practices by the companies. Therefore, this study critically examined the effect of corporate planning (strategic planning and strategy implementation) on organizational performance measured in terms of service quality in the Nigerian Telecommunication sector, with focus on MTN in the North Central zone, Nigeria. The outcome of this research would enable the management re-strategize and make arrangement for better coordination of the core areas of corporate planning that will lead to improvement in the quality of services rendered to their clients. 


\section{Methodology \\ Research Design}

The study adopted survey research design. The design enabled the researchers to collect relevant data through the use of structured questionnaire for the purpose of analysis in order to achieve the objectives of the study. Research design was measured quantitatively with the use of questionnaires, thereby allowing for testing of formulated hypotheses and drawing inferences.

\section{The Study Area}

The study for this study is North Central Nigeria. North Central Nigeria consists of the seven states situated geographically in the middle belt region of the country, spanning from the West, around the confluence of the River Niger and the River Benue. North Central Nigeria is made up of six States: Benue, Niger, Kogi, Kwara, Plateau and Nasarawa as well as the Federal Capital Territory Abuja.

\section{Population Sampling Technique of the Study}

The population of this study was made up of 133 MTN staff with work experience of three (3) years and above in the North Central region consisting of Benue, Nasarawa and Kogi States. Therefore, the population comprises of 32 staff for Benue State, Nasarawa State (48) and Kogi State (53). The reason for the purposive selection was to guarantee that the respondents would be able to provide reliable information on the subject under investigation.

\section{Instrument for Data Collection}

Structured questionnaire was used as instrument for data collection. The instrument was divided in three parts (A, B and C) and five sections in all. The first part 'Part A' has focused on the personal data of the respondents. 'Part B' dwelt on corporate planning at MTN. 'Part C' was on organizational performance with emphasis laid on service quality. The questionnaire had questions using five point Lickert scales ranging from strongly disagree to strongly agree and four point Lickert scale ranging from very low to very high.

\section{Validation of the Instrument}

The researcher made use of factor analysis to measure the significant dimensions of culture and provides them a rating on a comparison scale and maintains the independence of each variable. Factor analysis is a set of methods aiming to understand the influence of underlying constructs on a number of studied variables. Exploratory Factor Analysis (EFA) and Confirmatory Factor Analysis (CFA) were used to assess the construct validity of each variable in this study. Bartlett's test of Sphericity was employed to test the null hypothesis that the original correlation matrix is an identity matrix. At $1 \%$ level of significance, the results show that the data is highly significant $(\mathrm{p}<0.001)$, and therefore Factor Analysis is appropriate. According to the results from the KMO and Bartlett's Test, the Kaiser- Meyer- Olkin (KMO) which measured the sample adequacy was .656 while the Bartlett's Test of Sphericity was significant (App. chi-square $=84.362$, sig. $=$ .000) which indicates the sufficient inter correlations of the factor analysis. The KMO and Barlett's Test result was shown in Table 1.

\section{Reliability of the Instrument}

The researcher employed Cronbach's alpha to ensure reliability of the instruments. The Cronbach's alpha measured the internal consistency that is, how closely related a set of items are as a group. To ensure the reliability of the measurement instrument, a pilot test was carried out 44 entrepreneurs $\left({ }^{1 /}{ }_{3}\right.$ of $\left.133=44\right)$. The Cronbach's Alpha for each of the constructs was greater than .70. This implies that all the constructs were reliable and were therefore used in this study. The result in Table 2 showed the Cronbach's Alpha for each of the constructs.

\section{Data Analysis Techniques}

Both descriptive and inferential statistics were used to analyse the data for the study. Descriptive statistics such as frequency distribution and percentages were computed. Multiple regression analysis was used to 
test the hypotheses. The t- statistics measured the statistical significance of each independent variable while the F-statistic was used to measure the joint effect of the independent variables on the dependent variable. The analysis was done with aid of Statistical Package for Social Sciences (SPSS 20). The tests were conducted at the probability level of 0.05 .

\section{Results and Discussion}

Result showed that most of the workers (about 54\%) had 2-4years working experience with the organization while the longest length of service was approximately $12 \%$ of the work force. About $35 \%$ of the workers had stayed between 5 to 10 years as shown in table 3 .

Data obtained from the strategic planning of MTN is presented in Table 4. All the parameters measured were above the minimum agreeable benchmark of 3.5. The environment of the business affects its performance with a mean value of 4.12. The organization also has enough resources to help achieve its goal as average of 4.3 values was recorded on the lickert scale. This was the highest value recorded. The analysis of resources in the organization has helped improve the quality of services rendered on average scale of 4.25. This result implied that MTN adopted strategic analysis as a dimension of corporate planning in all its activities. The adoption of strategic analysis by MTN helped in improving the service quality of company. The strength of the relationship between strategic analysis (SA) and service quality (SQ) was measured by the calculated p-value (0.000) at a significance level $(\alpha)$ of 0.05 . The computed p-value was less than the significance level $(\alpha)$ of 0.05 ( $p$-value $0.000<\alpha 0.05)$, the null hypothesis was rejected. Strategic analysis had significant relationship with service quality in the studied organization. The computed p-value was also less than the significance level $(\alpha)$ of 0.05 ( $p$-value $0.000<\alpha 0.05)$, the null hypothesis was rejected. It was also concluded that strategy implementation had significant effect on service quality in MTN.

The analysis of the quality of service, as a dimension of organizational performance of MTN, is presented in Table5. All the seven indicators of service quality employed by the study indicated high results. The organization is reliable with good assurance (Figure 1). Network quality recorded the highest mean (3.71) as shown in Figure 2. Other results such as competitive advantage and reliability (3.22) attested to the high service quality of the organization. This result indicated that with the average service quality of 3.09, the corporate planning of MTN is oriented towards retaining customers through the provision of high quality of its service.

The result of the regression model for service quality as presented in Table 6 showed that the model was fit for estimation and the explanatory variables were properly selected. This was confirmed by the value of Fstatistics of $25.480(\mathrm{P}=0.000)$ being significant at $1 \%$ level of significance. The coefficient of determination of the model was $53.5 \%$. The result implied that $53.5 \%$ of the variation in service quality was explained by the influence of the independent variables in the model (strategic analysis and strategy implementation). The standard coefficient also indicated the statistical significance of the independent variables. The positive coefficient value of .286 implied that $1 \%$ increase in strategic analysis and strategy implementation resulted to $28.6 \%$ increase in service quality. The result also showed that there was a positive statistical relationship between strategic analysis and strategy implementation and quality of service offered by the Telecommunication sector.

The analysis of the data collected from the respondents revealed that strategic analysis had a positive significant relationship with service quality in the Nigerian Telecommunication sector. Regression was used to test the hypothesis at $5 \%$ level of significance and the p-value $(0.000)$ was lower than the significance level. This can be statistically given as P-value $0.000<\alpha=0.05$. Therefore the null hypothesis was rejected and it was concluded that strategic analysis had a strong relationship with service quality. The finding was in line with Grant (2003) and Akingbade (2014) who asserted strategic analysis assist telecommunication firms to identify strategies which enable them in the provision of quality services. This implied that strategic analysis was a prerequisite requirement for telecommunication companies to effectively increase their service quality such as efficient and effective communication, attractive and appealing products and offering of products that are relatively the best in the industry. 
From the analysis of the data collected from the researcher's field survey, it was observed that the respondents' opinion indicated strategy implementation had a positive significant relationship with service quality in the Nigerian Telecommunication sector. To confirm the findings above, regression was used to test the hypothesis at $5 \%$ level of significance and the p-value (0.000) was lower than the significance level 0.05 . This can be statistically given as P-value $0.000<\alpha=0.05$. Therefore the null hypothesis was rejected and the alternate hypothesis accepted. The finding correlate with Alamutu et al (2012) who suggested that strategy implementation creates a link between strategy formulation and expected outcomes and the successful execution of organizational strategies could boost organizational performance and reduce cost thereby improving the quality its services. These findings, however, negate the empirical findings by Alaka et al (2011) who found that most organizations fail to effectively implement strategies and this leads to unanticipated loss in their performance in terms of service delivery and market share.

Table 1: KMO and Barlett's Test

\begin{tabular}{|l|l|}
\hline \multicolumn{1}{|c|}{ Test } & Value \\
\hline Kaiser-Mayer-Oklin Measure of Sampling Adequacy & .656 \\
\hline Approx. Chi-Square & 84.262 \\
\hline Bartlett's Test of Sphericity & 15 \\
\hline Sig. & .000 \\
\hline
\end{tabular}

Table 2: Reliability Test Results

\begin{tabular}{|l|c|}
\hline \multicolumn{1}{|c|}{ Variable } & Cronbach's Alpha \\
\hline Strategic Analysis & 0.777 \\
\hline Strategy Implementation & 0.721 \\
\hline Service Quality & 0.710 \\
\hline Overall Reliability & 0.729 \\
\hline
\end{tabular}

Table 3: Length of Service Years among Workers

\begin{tabular}{|l|c|c|}
\hline Demographic Characteristics & Frequency & Percentage (\%) \\
\hline Length of service (years) & & \\
\hline $2-4$ & 70 & 53.8 \\
\hline $5-10$ & 45 & 34.6 \\
\hline $11-17$ & 15 & 11.5 \\
\hline Total & 130 & 100.0 \\
\hline
\end{tabular}

Table 4: Descriptive Statistics on Strategic Analysis

\begin{tabular}{|l|l|l|}
\hline Parameters & Mean & $\begin{array}{l}\text { Standard } \\
\text { Deviation }\end{array}$ \\
\hline The environment of the business affects its performance & 4.12 & 1.001 \\
\hline The values and objectives of the company are clearly stated & 4.04 & 1.007 \\
\hline There are enough resources in the company to help achieve its goal & 4.30 & 0.860 \\
\hline $\begin{array}{l}\text { The analysis of resources in the organization helps to improve quality of } \\
\text { services rendered }\end{array}$ & 4.25 & 0.883 \\
\hline
\end{tabular}

Decision rule:

If mean $<3.0$ the respondents Disagree

If $3.0 \leq$ mean $<3.5$ the respondents are Undecided

If mean $\geq 3.5$ the respondents Agree

Table 5: Service Quality

Service quality indicators Mean Standard Deviation 


\begin{tabular}{|l|c|c|}
\hline Tangibility & 3.19 & 0.94 \\
\hline Reliability & 3.22 & 0.97 \\
\hline Responsiveness & 2.84 & 1.03 \\
\hline Assurance & 3.15 & 0.97 \\
\hline Empathy & 2.31 & 1.17 \\
\hline Network quality & 3.71 & 0.70 \\
\hline Competitive advantage & 3.22 & 0.97 \\
\hline Service quality & 3.09 & 0.72 \\
\hline
\end{tabular}

Table 6: Regression Model for Service Quality

\begin{tabular}{|l|l|l|l|l|}
\hline Variable & Coefficient & St. Error & t-Statistic & Prob \\
\hline Constant) & 1.320 & .417 & 3.166 & .000 \\
\hline Strategic Analysis & .417 & .073 & 5.692 & .000 \\
\hline $\begin{array}{l}\text { Strategy } \\
\text { Implementation }\end{array}$ & .254 & .071 & 3.590 & .000 \\
\hline
\end{tabular}

a. Dependent Variable: Service Quality $* *$ Correlation is significant at the 0.01 level (2-tailed), $\mathrm{F}$ Calculated value $=25.480$ at $0.05, \mathrm{R}^{2}=53.5 \%$.

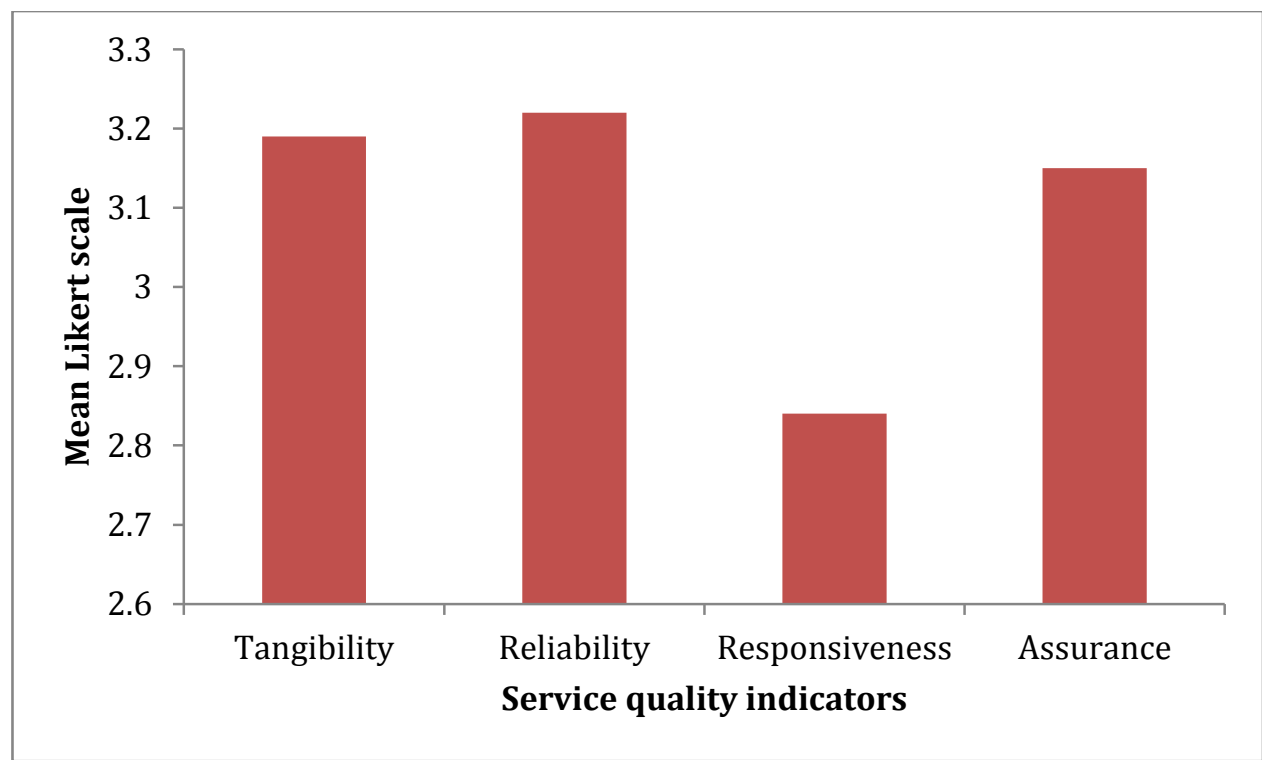

Figure 1: Reliability and Assurance as Service Quality Indicators 


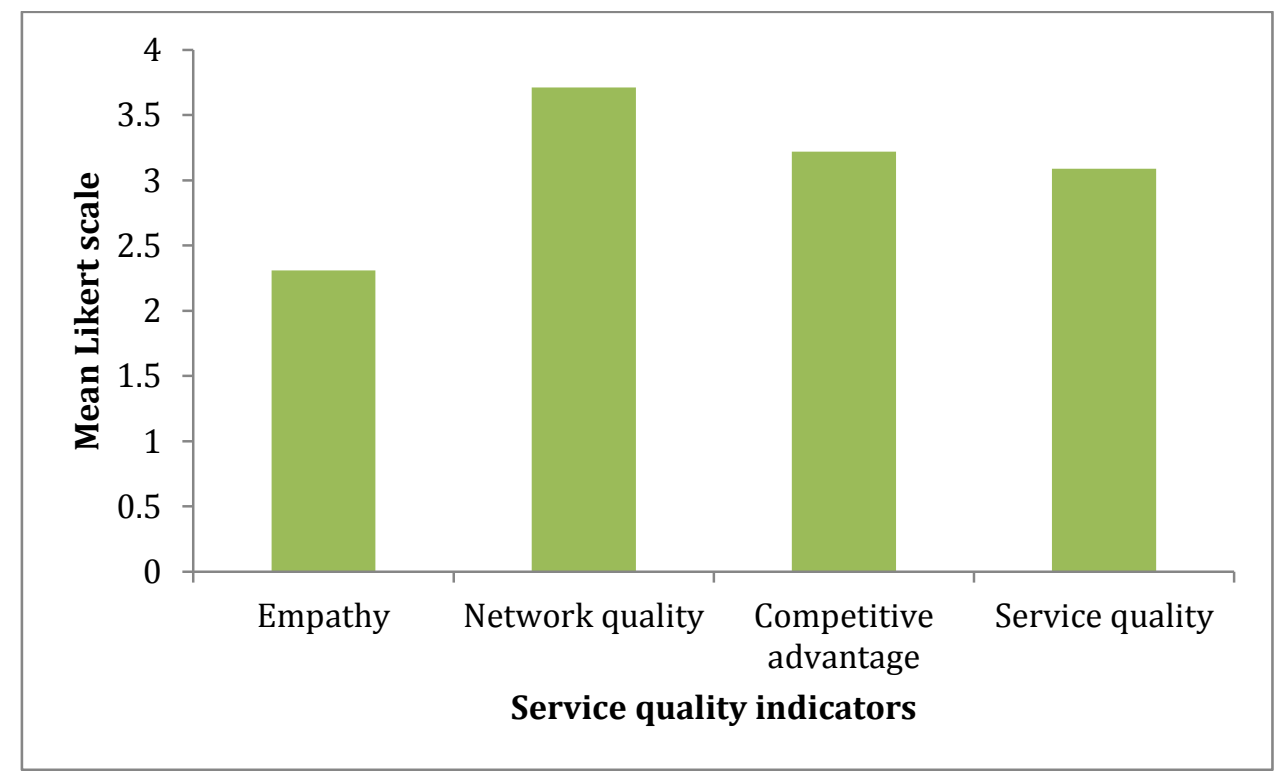

Figure 2: Network Quality, Competitive Advantage and Service Quality

\section{Conclusion}

Strategic analysis had a positive significant relationship with service delivery in Nigeria telecommunication sector $(\mathrm{P}$-value $0.00<\alpha 0.05)$. Strategy implementation had a positive significant relationship with service quality in the Nigerian telecommunication sector $(\mathrm{P}$-value $0.000<\alpha 0.05$ )

\section{References}

[1] Akingbade, W. A. (2014). Competitive Strategies and Improved Performance of Selected Nigeria Telecommunication Companies. Journal of Management and Social Sciences, 2(3):143-168

[2] Alaka, N.S., Tijani, A.A. and Abass, O.A. (2011).Impact of strategic planning on the performance of insurance companies in Nigeria. European Journal of Humanities and Social sciences, 5(1):23-39.

[3] Alamutu, S. A., Hotepo, O. M., Oyeobu, A. J., and Nwatulegwu, B. I. (2012). An evaluation of total quality management practices on business performance of the Nigerian telecommunications sector: a case study of MTN Nigeria Limited History Management of Total Quality Overview of telecommunications sector Nigerian. LASU, Department of Business Administration and Management Technology, 1(2):155-166.

[4] Ansoh, H.H., Miller, C.C. and Cardinal, L.B. (2001). Corporate Planning and Firm Performance: A synthesis of more than two decades of Research. Academic Management Journals, 37 (4):1649-1665.

[5] Armstrong, J.S. (1995). The Value of Formal Planning for Corporate Decision: Reply, Corporate Management Journal, 7 (4):183-185.

[6] Gerad, Y.M., Abdullahi, S.M. and Bashir, H.M. (2015). The Relationship between Strategic Management and Organizational Performance in Mogadishu-Somalia. European Journal of research and Reflection in Management Sciences, 3(2):42-51.

[7] Griffins, L. W. (2006). Strategic planning: concept and cases. Strategic Management Journal, 16(2):71-83.

[8] Hax, A. C. and Majluf, N. S. (1996). The strategy concept and process: a pragmatic approach. (2nd edn.) New Jersey: Prentice-Hall. 214 Pp

[9] Imaga, E.U.L. (1996): A Manual of Corporate Planning and Strategic Business Policy, Raye Kere Publishers, Enugu. 179 Pp.

[10] Mohammed, S.R. and John, M. (2012). The Study on Corporate Planning and Organizational Performance in the Regional Government Owned Banks in Indonesia. International Journal of Humanities and Applied Sciences, 1(3): 98-102.

[11] Porter, M.E. (1985). Competitive advantage ( $3^{\text {rd }}$ edn.). New York: Free press. 96 Pp

[12] Richard, S. (2002). Organizational Behaviours Concepts Controversies Applications, (4 ${ }^{\text {th }}$ edn.). New Jersey: Prentice Hall. $256 \mathrm{Pp}$ 